\title{
Curriculum Reform and Practice of Mechanical CAD/CAM Technology
}

\author{
https://doi.org/10.3991/ijet.v13i08.9040 \\ Xin Li \\ Agricultural University of Hebei, Baoding, China \\ lixin20131113@163.com
}

\begin{abstract}
Mechanical CAD/CAM technology is an important course for the mechanical design and manufacturing major. Its scope has a wide teaching content and discipline span, and is regarded a comprehensive course with strong theoretical and practical characteristics. Theoretical teaching was emphasized in the past to undervalue software operation. Unpractical teaching content directly resulted in student's insufficient practice after the course. Thus, teaching reform measures were proposed, such as optimizing teaching contents, implementing modular teaching, introducing skill-based software, and formulating typical work tasks. Combined with theoretical knowledge, students used the software as a tool to accomplish designated tasks and reach corresponding teaching objectives. Taking mouse punch as an example, MasterCAM software was used to introduce the specific mode of task-oriented teaching in CAD/CAM experiments. Results show that students improve their abilities of applying CAD/CAM software after the course's teaching reform. Practical engineering problems are analyzed thoroughly and orderly. Employment quantity and quality of graduates are significantly improved to gain praises from enterprises and achieve a remarkable teaching effect.
\end{abstract}

Keywords-mechanical CAD/CAM technology, teaching reform, practical ability, task

\section{Introduction}

With the development of advanced manufacturing technology, CAD/CAM technology has become the core of modern manufacturing technology, which greatly improves the design, manufacturing, and management of enterprises. This technology is considered as the key to improving manufacturing productivity and product competitiveness. CAD/CAM also becomes an indispensable professional skill for mechanical engineers. Mechanical CAD/CAM Technology is a professional course for mechanical design, manufacturing, and automation majors, which covers CAD, CAM, CAE, and CAPP based on Mechanical Drawing, Basis of Mechanical Design, Mechanical Manufacturing Technology, and CNC Machining Technology and Programming. Therefore, the course has knowledge-intensive, interdisciplinary, comprehensive, and practical characteristics. Massive disciplines and extensive content bring 
difficulty to teaching. This course cannot be introduced in detail within a limited class time because expanding students' knowledge require a conducive environment. However, expository teaching cannot stimulate the learning enthusiasm and creativity of students. The process of finding the main line throughout teaching activities to improve the quality of teaching needs to be solved; the thread that runs through the whole teaching activity, which improves teaching quality, must be found [1].

In the past teaching process, the teaching content was heavily oriented toward theory. Students feel bored because of excessive theoretical exposition, which ignores subjective initiatives. However, students cannot master relevant theoretical knowledge from the explanation of basic software applications and thus fails to satisfy the sustainable development of students. Therefore, mechanical CAD/CAM courses and teaching methods must be reformed to make the teaching process serve the enterprise's requirements for students and to cultivate highly skilled and creative talents.

\section{State of art}

Domestic and foreign universities have explored the course system by teaching contents and teaching methods of mechanical CAD/CAM technology courses. Some universities have focused on teaching the secondary development of $\mathrm{C}$ language program experiments and applications. For example, Wright (1986) offered a mechanical $\mathrm{CAD} / \mathrm{CAM}$ course that covered two-dimensional software drawing and industrialoriented software development [2]. A specialist only masters his/her own field. Teachers should take the practicability of mechanical CAD/CAM technology as fundamental. Therefore, students can apply the CAD/CAM software to design and process products based on the basic principle of CAD/CAM. The main content is software application rather than software development. Moreover, mechanical students are not rigorously trained in software development and database. Great difficulties exist in learning, which directly affects the enthusiasm for learning. Learning software development and database deviates from the future employment direction of students. Therefore, teachers only briefly introduce and not deeply discuss the concept. Teachers should focus on curriculum teaching and practical operation, which play an effective role in future employment.

In theoretical teaching, Guo (2007) established the relationship between 2D and 3D graphic homologous transformation matrices combined with graphs and tables and thus obtained the evolution relations among transformation, canonical, and unit matrices [3]. Qi (2013) used the coordinate substitution method to rapidly solve the rotation transformation of 3D graphics [4]. These methods are introduced in the teaching for the understanding and recollection of students. However, the course is still taught in the traditional way in some domestic colleges. The teachers overemphasize the theoretical knowledge of mechanical CAD/CAM technology, which neglects practical operation. Therefore, students are short of application abilities although the concept and principle are understood and the application ability is lacking. Theory is integrat- 
ed with practice to deepen students' understanding of theoretical knowledge, which enhances their competitive advantages in the talent market.

Document literature shows that universities are mainly based on the CAD model design in the practical course of software operation. Peng (2009) expounded the teaching reform of a $3 \mathrm{D} \mathrm{CAD/CAM} \mathrm{course} \mathrm{based} \mathrm{on} \mathrm{curriculum} \mathrm{setting,} \mathrm{teaching}$ mode, and material compilation, which improves 3D modeling and the map recognition abilities of students [5]. Hu (2002) explored the importance of 3D modeling technology to engineering modeling and the spatial thinking abilities of students [6]. Most courses focus on a single part design. The theoretical explanation of CAE and CAM is greater than practical explanation. Therefore, students can only use the drawing software in the company. Reflecting the learning value of the course is difficult.

Some universities enrich CAD/CAM practice teaching links using a series of means. For example, Pan (2017) introduced the design competition into CAD/CAM course to construct the CAD/CAM course standard for competition and teaching [7]. Zhang (2013) organized students to participate in professional competitions by assigning a "Big homework" [8]. Yu (2009) closely interspersed the experiments in the classroom teaching process after adding the computer experiment course [9]. Hideki (2011) brought the programming of five-axis machining tool into the CAD/CAM course [10]. Du (2014) proposed the reorganization of teaching resources to enhance the practical teaching [11]. Students' autonomous learning abilities are stimulated to cultivate manipulative and innovation abilities. Juan (2013) developed graphics engineering teaching methods based on the simulation of a mechanal motion in Universidad De Salamanca [12]. The application capacities of students are effectively improved by these methods to a certain extent, but systematization and comprehensiveness are still lacking.

The course is conducted with a teaching reform to refine the teaching goal after the teaching survey of mechanical CAD/CAM technology curriculum at home and abroad. The students can learn the necessary knowledge modules to rebuild the teaching content. First, the complex theoretical knowledge has been closely organized according to the actual production needs. The teaching content is optimized to divide the teaching module, which enables students to understand $\mathrm{CAD} / \mathrm{CAM}$ core knowledge. Second, the computer practices of students are emphasized. Students can solve practical problems with innovative spirit to break the unitary teaching idea by formulating typical tasks. The teaching forms are enriched to develop the initiatives of students.

\section{Teaching mode after the reform of mechanical CAD/CAM technology curriculum}

Mechanical CAD/CAM technology teaching is characterized by extensive teaching content and subject span. Therefore, we should grasp the key points of the teaching design and thinking. The theoretical knowledge is integrated with practical skills and application environment. The teaching mode is designed to train students' comprehen- 
sive abilities to complete the whole task. The basic idea of the research project reform is described as follows.

\subsection{Design of modular teaching process}

Based on relevant knowledge and skills, the teaching content is optimized by taking product design, modeling, technology analysis, and CNC programming as the teaching mainline. Students fully understand the entire process of product design and production after the theoretical learning and practical skill training of the whole process (part pattern analysis, 2D drawing, solid modeling, process design, simulation processing, and automatic programming). The advanced manufacturing technology is comprehensively mastered to cultivate abilities to analyze and solve problems [1314].

According to the teaching contents of mechanical CAD/CAM technology, the process is divided into four teaching modules: CAD, CAE, CAM, and CAPP (Figure 1).

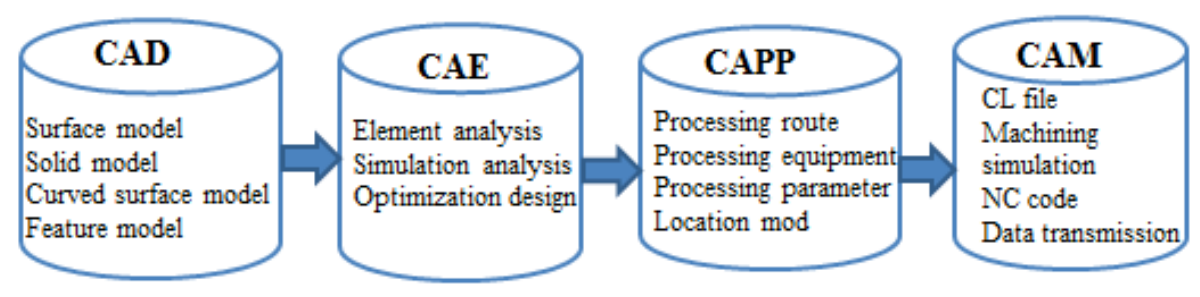

Fig. 1. $\mathrm{CAD} / \mathrm{CAM}$ integrated teaching process

Module 1: CAD. Geometric modeling technology, the source of product information, defines the digital model and digital and graphic information of the product in the computer. The technology also provides effective information for product design analysis, drawing generation, numerical control programming, processing simulation, and production process management. Geometric modeling technology is the precondition of achieving CAD/CAM and the integration. Students are required to master the concepts and methods of 2D drawing and 3D modeling, and the method of feature modeling for the manufacturing process. Moreover, the students can use modeling software, which includes Pro/E, UG, and Solidworks, to quickly sketch and edit 2D graphics. The appropriate modeling method is selected to conduct 3D modeling, assembly, and the simulation of parts according to the design drawings.

Module 2: CAE. Numerical simulation technology is used to analyze product performance and safety reliability, which simulates its future work status and operation behavior. The design deficiencies are found and modified early to verify the feasibility and reliability of functionality and performance, which achieves product optimization. Finite element analysis is the most difficult in this module. The basic idea is to discretize the complex continuous body into finite units. All forces on the units are equivalently replaced by the node loads to establish the unit balance equation, which obtains node displacement, force, and unit stiffness matrices (Equations (1), (2), and (3)). 


$$
\begin{gathered}
\phi^{i}=\left\{\begin{array}{c}
u_{i} \\
u_{i+1}
\end{array}\right\} \\
F^{i}=\left\{\begin{array}{c}
F_{i}^{i} \\
F^{i}{ }_{i+1}
\end{array}\right\}=\frac{E A}{L_{i}}\left[\begin{array}{cc}
1 & -1 \\
-1 & 1
\end{array}\right]\left\{\begin{array}{c}
u_{i} \\
u_{i+1}
\end{array}\right\}=K^{i} \phi^{i} \\
K^{i}=\frac{E A}{L_{i}}\left[\begin{array}{cc}
1 & -1 \\
-1 & 1
\end{array}\right]
\end{gathered}
$$

The stiffness matrices of units are integrated into the total stiffness matrix. The unit force vectors of units are also integrated into the total force vector, which obtains the global balance equation. Finally, the boundary constraints are determined to solve the equation set. Students are required to understand the basic principles, steps, and algorithms of finite element analysis. Furthermore, students should grasp the principles, methods, and software operation steps of pre-processing and post-processing, which optimize common engineering problems.

Module 3: CAPP. Process planning is an important technical preparation for machinery manufacturing, and it transforms product data into manufacturing-oriented mandatory data, which bridges the applications of CAD and CAM. This link requires students to conduct the process analysis of the 3D model by specifying the processing content, method, route, and technical requirements. The equipment is selected to calculate cutting parameter, machining allowance, procedure size, tolerance, and manhour quota. The process documents are filled by determining the cutters, fixtures, measuring tools, and clamping positioning methods of parts.

Module 4: CAM. Students are required to use software, such as CNC programming software MasterCAM, Pro/E, and UG. We set the cut-in and exchange points to select the reasonable processing method according to the process file. The appropriate cutting parameters are set to generate tool paths and process simulation. A specific $\mathrm{CNC}$ is conducted with post-processing to generate an NC program code.

Based on module organization teaching, we obtain more systematic teaching content with highly consistent knowledge and efficient teaching.

\subsection{Construction of mechanical CAD/CAM technology teaching method based on working process}

The Ministry of Education has implemented "the Project of Cultivating Skilled Talents in Manufacturing Industry and Modern Service Industry" since 2003. The purpose of professional learning is to master "the ability of independently solving professional problems by professional knowledge and skills." The teaching contents focus on "working process knowledge and skills with certain empirical natures required in the actual work." A comprehensive curriculum teaching according to the work process is required.

A typical work task consists of one or several learning tasks. The students' comprehensive professional abilities are promoted by completing the process of typical 
work tasks. The core is to find a suitable carrier for learning content. Typical tasks are established to provide students with comprehensive working assignment and process, where the theory is integrated with practice. The corresponding learning situations under all typical tasks are designed according to the difficulty of parts. Multiple learning tasks are established in the learning process from simple to complex, from easy to difficult, and from single to comprehensive.

The mechanical CAD/CAM technology course is oriented to the entire process of the design, analysis, and manufacturing. In the teaching process, students are guided to complete the overall tasks, thus cultivating students' overall professional abilities. We establish course content and the typical tasks of integrated teaching and learning field according to the modular teaching design process. The courses are organized based on the target task, which enables students to acquire relevant theoretical knowledge in the process of completing the target task. The comprehensive abilities of students are developed to cultivate abilities to independently analyze and solve problems.

When the course reaches a certain level, the students have a basic grasp of the modeling software operation, relevant concepts, and methods in the mechanical CAD/CAM technology. The design tasks are issued to the students in the form of task books. For example, a gear hydraulic pump is conducted with 3D modeling and virtual assembly. The task is divided into part modeling, virtual assembly, engineering analysis, virtual simulation, and machining. Students are grouped. Each group has a team leader who assigns tasks. Moreover, the $3 \mathrm{D}$ gear modeling is difficult in this task. The teacher gives appropriate tips on gear modeling when assigning a task. Therefore, students solve the problems by themselves through the Internet and reference books. In this process, students constantly obtain a sense of accomplishment for stimulating their desire for knowledge, which develops their self-learning abilities.

\section{$4 \quad$ Teaching case and effect}

\subsection{Teaching case}

Based on MasterCAM 9.1 software of the CAD/CAM integrated system, the $\mathrm{CAD} / \mathrm{CAM}$ technology is used for mouse punch modeling and NC programming, which avoids the frequent interchange between CAD and CAM. Moreover, this type of technology solves the data loss problem caused by the data format conversion of the software.

Model of mouse punch. According to the design drawings, the mouse punch model is established by surface modeling method (Figure 2). After creating the line graph, the students exercise in drawing 2D graphics (such as lines, arcs, chamfers, and rectangles), and editing operations (such as mirroring, pruning and deleting). The top and side surfaces of the mouse punch are created by the curved surface scanning and stretching, respectively. The normal directions of the top and side surfaces are adjusted to create the fillet surface of the mouse punch. The boundary surface is finally used to build the mouse punch base. Through this modeling exercise, students can deeply 
understand the modeling method and the directionality and composition of the surface. We understand the concepts and creating methods of boundary plane, scanning, drawing, fillet, and ruled surfaces in practice.

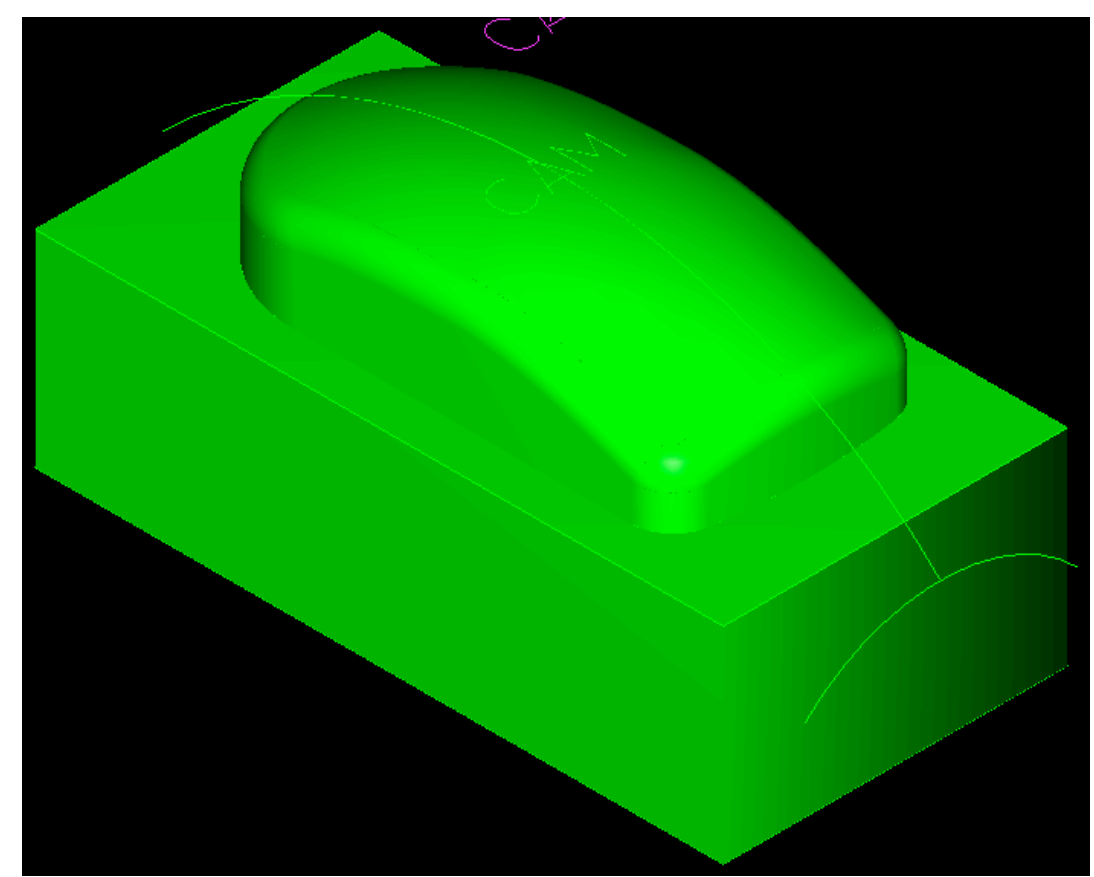

Fig. 2. Mouse punch model

Mouse punch process analysis. According to the product design results, the semifinished products are selected to develop processing methods, steps, equipment, and parameters, which provide the basis for numerical control programming. The students select 45 steel work pieces, with the blank sizes of $100 \mathrm{~mm} \times 50 \mathrm{~mm} \times 50 \mathrm{~mm}$. Plain vice is used to clamp the workpiece in a machining center. The mouse is $20 \mathrm{~mm}$ high. Thus, the blank should be approximately $25 \mathrm{~mm}$ above the jaw. The machining coordinate is set as follows. The origins of $\mathrm{X}$ and $\mathrm{Y}$ axes are at the midpoint of the model. The origin of the $\mathrm{Z}$-axis is at the plane where the highest point of the model is located. The processing card shows CNC machining routes and tool settings (Table 1).

NC programming of mouse punch. First, the punch profile and surface are conducted with rough machining by a plane shape and surface contouring roughing method. A flat cutter $\Phi 16$ is selected as the tool, which leaves $1.5 \mathrm{~mm}$ margin. With a small machining allowance, the curved surface parallel finishing is used to conduct the semi-finishing of the convex surface, which reduces knife lifting times and improves processing efficiency. Ball-end cutter $\Phi 10 \mathrm{R} 5$ is used as the tool, which leaves a $0.3 \mathrm{~mm}$ margin. End mill $\Phi 16$ is used for contour finishing. The overlap of knives in the down milling process is $3 \mathrm{~mm}$. Before processing, the chips are cleaned to prevent being involved in the tools. The main shaft speed and cutting feed cannot be adjusted 
to avoid affecting the surface quality. Finally, ball-end cutter $\Phi 10 \mathrm{R} 5$ is used for surface finishing, which leaves a $0 \mathrm{~mm}$ margin. The cutting angle is perpendicular to semi-finishing with a good surface effect. We conduct machining process simulation before generating the NC program. The product manufacturing process is simulated to verify the rationality and feasibility of processing methods, which avoids damage and reduces investment risk. Figure 3 shows the simulation results. Post-processing is then conducted to generate an NC machining code (Figure 4).

Table 1. Mouse punch $\mathrm{CNC}$ machining process card

\begin{tabular}{|c|c|c|c|c|c|}
\hline \multirow{2}{*}{\multicolumn{2}{|c|}{$\begin{array}{c}\text { CNC Machining Process } \\
\text { Card }\end{array}$}} & \multicolumn{2}{|c|}{ Part Name } & \multirow{3}{*}{\begin{tabular}{|c|} 
Clamp Name \\
Plain Vice \\
Feed \\
Speed $(\mathrm{mm} \cdot \min$ \\
$-1)$
\end{tabular}} & \multirow{3}{*}{$\begin{array}{c}\text { Material } \\
45 \text { Steel } \\
\begin{array}{c}\text { DOC } \\
(\mathrm{mm})\end{array}\end{array}$} \\
\hline & & Mouse Pun & & & \\
\hline $\begin{array}{l}\text { Work Step } \\
\text { No. }\end{array}$ & $\begin{array}{l}\text { Work Step } \\
\text { Content }\end{array}$ & $\begin{array}{l}\text { Tool Specification } \\
(\mathrm{mm})\end{array}$ & $\begin{array}{l}\text { Main Shaft Speed } \\
\left(\mathrm{r} \cdot \mathrm{min}^{-1}\right)\end{array}$ & & \\
\hline 1 & $\begin{array}{l}\text { Contour } \\
\text { Rough } \\
\text { Machining } \\
\end{array}$ & $\begin{array}{l}\text { End Mill made by High- } \\
\text { speed Steel } \Phi 16\end{array}$ & 600 & 300 & -20 \\
\hline 2 & $\begin{array}{l}\text { Curve } \\
\text { Contour } \\
\text { Rough } \\
\text { Machining }\end{array}$ & $\begin{array}{l}\text { End Mill made by High- } \\
\text { speed Steel } \Phi 16\end{array}$ & 600 & 300 & Depth 1 once \\
\hline 3 & $\begin{array}{l}\text { Surface } \\
\text { Semi- } \\
\text { finishing }\end{array}$ & $\begin{array}{l}\text { Ball-end Cutter Made by } \\
\text { High-speed Steel } \Phi 10 R 5\end{array}$ & 2000 & 500 & $\begin{array}{l}\text { Vertical Spac- } \\
\quad \text { ing } 0.5\end{array}$ \\
\hline 4 & $\begin{array}{l}\text { Contour } \\
\text { finishing }\end{array}$ & $\begin{array}{c}\text { New End Mill made by } \\
\text { High-speed Steel } \Phi 16\end{array}$ & 600 & 300 & -20 \\
\hline 5 & $\begin{array}{l}\text { Surface } \\
\text { finishing }\end{array}$ & $\begin{array}{c}\text { New Ball-end Cutter } \\
\text { Made by High-speed Steel } \\
\Phi 10 \mathrm{R} 5\end{array}$ & 3000 & 600 & $\begin{array}{l}\text { Vertical Spac- } \\
\quad \text { ing } 0.2\end{array}$ \\
\hline
\end{tabular}

The students can learn the entire part modeling, process parameter formulation, and process programming from practice to understand the meanings of CAD/CAPP/CAM integration. This approach also enhances the systematic nature and completeness of the course. 


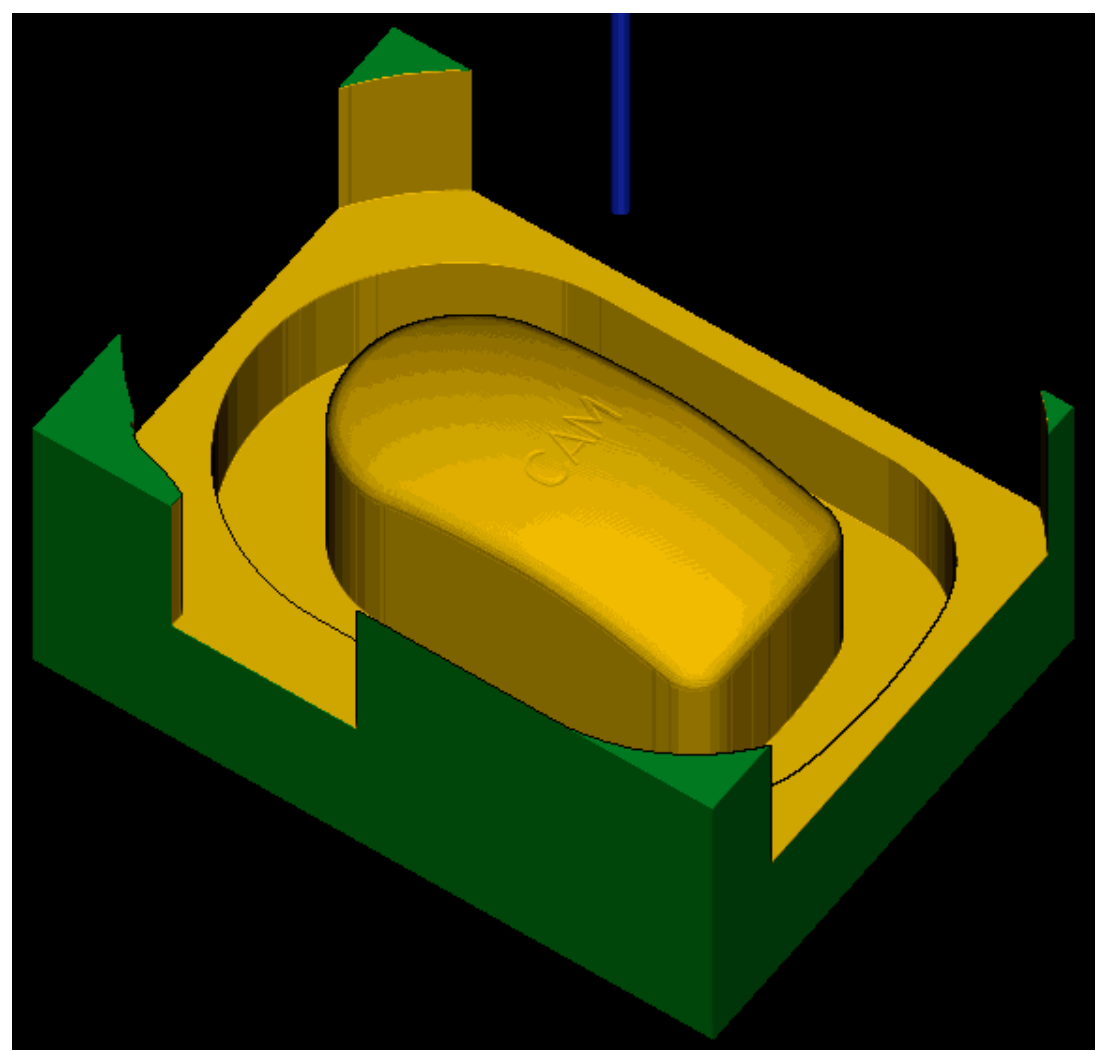

Fig. 3. Simulation result of punch machining

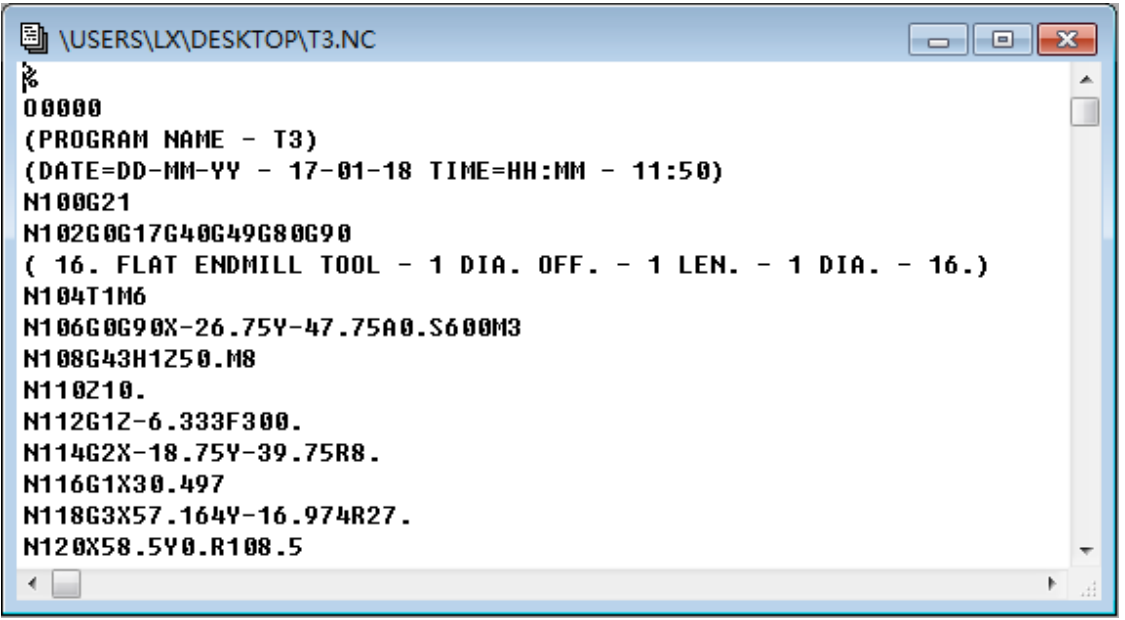

Fig. 4. Punch CNC machining code 


\subsection{Teaching effect}

The teaching reform of mechanical CAD/CAM technology course in 2016 was carried out for the two undergraduate classes of Grade 2013 in Mechanical Manufacturing and Automation. The number of students in each experimental class is controlled within 30 to improve the teaching effect. The course reform has been positively affirmed by college teachers, business experts, and students. The questionnaire data are statistically analyzed after the questionnaire survey and the employment tracking of students at Grades 2013 and 2012 (Figure 5).

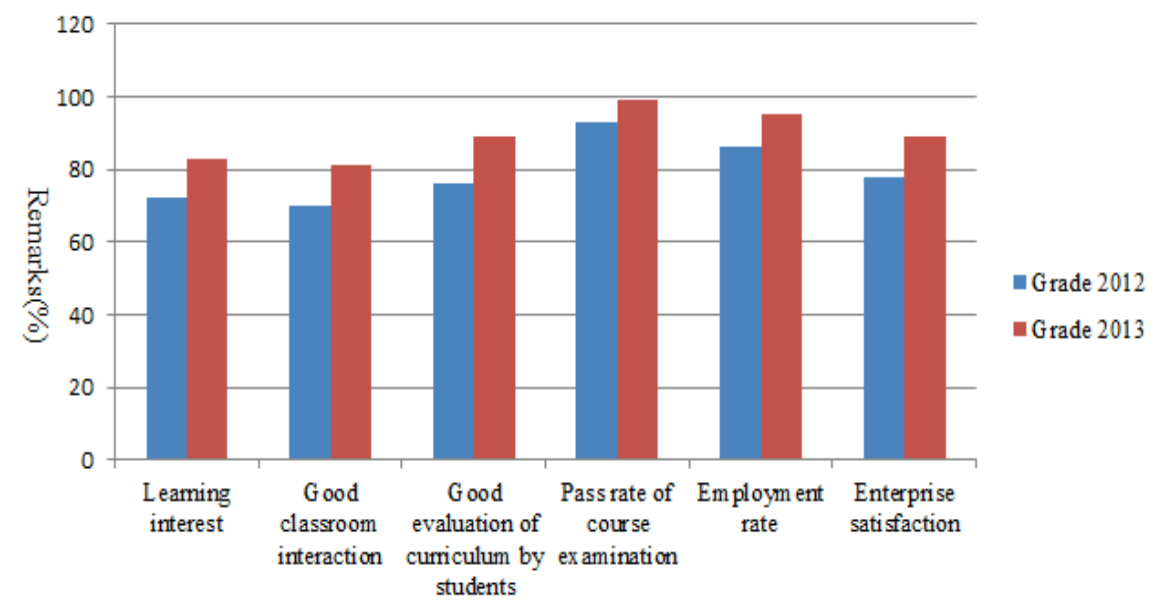

Fig. 5. Teaching investigation results

The results show that the initiatives of students are improved through the reform of the mechanical CAD/CAM technology course. The students believe that the course content is substantial, practical, and helpful to employment. The enterprises affirm software application, innovation, and ability to solve the actual production problems, which fully proves the teaching effect after curriculum reform.

\section{Conclusions}

The mechanical CAD/CAM technology courses were interspersed in the various modules of teaching content for exploratory reforms and practices using task-oriented teaching methods. The above reform measures contributed to improving the teaching quality of the course and student employability by comparing the class performance of former students, teaching feedback information, and student evaluation. The following conclusions could be drawn.

1. The task-oriented teaching method changed the previous "teaching-based" mentality to form the idea of "teaching interaction and student-centeredness." Students were encouraged to improve their enthusiasm from passive learning to active learn- 
ing by handing over the task achievements. The actual production tasks of enterprises were brought into the classroom to broaden horizons and thoughts of students, which lays the foundation for employment.

2. The students actively analyzed part modeling and processing methods combined with the basic theory and computer practice. For example, students were actively thinking in group discussions about "modeling technology." Different modeling solutions were proposed to discuss a specific part, which greatly improves students' skills in using modeling techniques. Through software teaching, students experienced the whole process from product design and analysis to code generation, which enhanced students' employment confidence and their desire for production practice.

3. The course content was selected to divide teaching modules, where the corresponding applications are introduced to improve the learning enthusiasm of students. Students deeply understood the basic principles and concepts of mechanical CAD/CAM technology based on the practical operation. Practical problems combined with specific tasks were effectively solved in the production process, such as problems in design and manufacturing. The application of software also provided the students with a platform, where innovative abilities were expanded.

\section{Acknowledgment}

This study was supported by the teaching research project of Agricultural University of Hebei (Grant No. 2015YB23, No. 2018YB26).

\section{$7 \quad$ References}

[1] Jin Ning, Jiao Li and Liu Yubo. Current situation and course teaching reform of CAD / CAM, Journal of Liaoning Technical University, 2010, vol. 29, pp. 203-204.

[2] I. C. Wright. Education and Training Packages for CAD/CAM, European Journal of Engineering Education, 1986, vol. 11(2), pp. 107-114. https://doi.org/10.1080/0304379860 8939287

[3] Guo Yuqin, Chang Yanwei and Gong Yanjue. Study on teaching methods of "graphics transformation" in cad / cam curriculum, Higher Education Forum, 2007, vol. 3, pp. 51-54.

[4] Qi Jiangbo. How to make students better grasp the rotation transformation in CAD / CAM, Education Forum, 2013, vol. 45, pp. 101-102.

[5] Peng Hongxing. Reflections on the teaching reform of 3D CAD / CAM, Education and Teaching Research, 2009, vol. 10, pp. 115.

[6] HU Qingni, DAI Hengzhen, GAO Fei and CUI Changde. Research of the course teaching reform in mechanical drawing course for 3D CAD/CAM, Journal of Engineering Graphics, 2002, vol. 1, pp. 137-142.

[7] Pan Dewen. Teaching reform of higher vocational courses based on industrial design contest - a case study of CAD / CAM curriculum, Journal of Liaoning Higher Vocational Colleges, 2017, vol. 19(3), pp. 27-28. 
[8] Zhang Deqiang, Li Jinhua and Li Tiejun. Exploration and practice of the course teaching reform of mechanical CAD / CAM, Journal of Liaoning Technical University, 2013, vol. 15(6), pp. 128-131.

[9] YU Yuan and LEI Wen. Teaching reform practice and exploration of CAD / CAM course, Journal of Beijing University of Chemical Technology, 2009, vol. 4, pp. 83-85.

[10] Hideki KUMA, Akiyasu TAKAMI, Shinya OKUHARA, Masakazu HONDA and Kazuhiro UCHIMURA. A planning and practice of CAD/CAM Course using a five-axis machine, Proceedings of Annual Conference of Japanese Society for Engineering Education $\square$ 2011, pp. 420-421.

[11] Du Yixian, Tian Qihua, Du Xuan and He Kongde. CAD/CAM courses integration of theoretical teaching and practical training, Procedia-Social and Behavioral Sciences, 2014, vol. 116, pp. 4297-4300. https://doi.org/10.1016/j.sbspro.2014.01.935

[12] Juan Carlos Pérez-Cerdán, Miguel Lorenzo, Alejandro Reveriego and Carmen Blanco. Innovative approach for teaching graphical engineering focused on CAD/CAM/CAE systems, Key Engineering Materials, 2013, vol. 572, pp. 311-314. https://doi.org/10.4028/ www.scientific.net/KEM.572.311

[13] Zhang Yunbin. Application of CAD/CAM/ NC integrated technology in higher vocational education. Kunming, China: Kunming University of Science and Technology, 2011.

[14] Feng Fang. CAD/CAM teaching issues and prospects for its development, Manufacturing Automation, 2010, vol. 32(10), pp. 119-121.

[15] Wang Bin. Teaching reform of CAD / CAM course under the guidance of competition: a case study of computer aided design and manufacturing of machinery products, Vocational Education Newsletter, 2015, vol. 18, pp. 23-24.

\section{Authors}

Xin Li is a lecturer in the College of Electrical and Mechanical Engineering, Agricultural University of Hebei, Baoding 071001, China (lixin20131113@163.com)

Article submitted 16 April. 2018. Resubmitted 23 June 2018. Final acceptance 11 July 2018. Finla version published as submitted by the author. 